\title{
Understanding Transmedia Music on YouTube through Disney Storytelling
}

\author{
Arantxa Vizcaíno-Verdú ${ }^{1, *(D)}$, Ignacio Aguaded ${ }^{1}\left(\mathbb{D}\right.$ and Paloma Contreras-Pulido ${ }^{2}$ (D) \\ 1 Department of Pedagogy, University of Huelva, 21007 Huelva, Spain; aguaded@uhu.es \\ 2 Department of Education, International University of La Rioja, 28040 Madrid, Spain; \\ paloma.contreras@unir.net \\ * Correspondence: arantxa.vizcaino@dedu.uhu.es
}

Citation: Vizcaíno-Verdú, A.; Aguaded, I.; Contreras-Pulido, P. Understanding Transmedia Music on YouTube through Disney Storytelling. Sustainability 2021, 13, 3667. https:// doi.org/10.3390/su13073667

Academic Editor: Gisela Cebrián

Received: 11 February 2021

Accepted: 22 March 2021

Published: 25 March 2021

Publisher's Note: MDPI stays neutral with regard to jurisdictional claims in published maps and institutional affiliations.

Copyright: (c) 2021 by the authors. Licensee MDPI, Basel, Switzerland. This article is an open access article distributed under the terms and conditions of the Creative Commons Attribution (CC BY) license (https:/ / creativecommons.org/licenses/by/ $4.0 /)$.

\begin{abstract}
Transmedia storytelling has been integrated into contemporary society through social media, where influencers have enabled the building of worlds. Within this environment of humaninteraction, fiction and converging social realities have become an essential tool to tell stories. On YouTube, storytelling has expanded to music, where cover videos take on great relevance. The aim of this study is to understand the transmedia music phenomenon due to the impact of music on the platform. To this end, we applied a methodology that stemmed from Grounded Theory principles in the analysis of 300 Disney animation song covers in three stages: (1) deductive and inductive codebook development; (2) social network analysis; and (3) statistical test. The results showed that youtubers highlight specific audiovisual codes from the film and cultural industries. Furthermore, we observed these productions often display configurations that expand the original story through performance, location, costumes, make-up, among others. We argue that, on the digital sphere, a sustainable transmedia music paradigm is developing, where performers construct more meaningful and valuable stories.
\end{abstract}

Keywords: transmedia music; music storytelling; musicking; transmedia storytelling; YouTube

\section{Introduction}

In the past, telling a story was a joyful experience. Fairytales, myths, and family anecdotes were part of people's culture and memories [1]. Currently, we live in an environment where social media has changed human relationships through diversified communication patterns. These stories, which today build parallel fictional universes, full of characters, places, and multiple realities, have spread across digital platforms as part of what scholars have termed transmedia storytelling.

Transmedia music is a concept that was initially proposed by Stuart Sanders Smith in 1975 to describe a musical composition comprised of different musical instruments and genres, and the concept expanded and changed over the years under different conceptualizations [2]. For example, the term transmedia intertextuality was developed to illustrate the relationships between different platforms, such as television, video games, cinema... [3]. However, the concept of transmedia storytelling was established much later [4]. This notion represents the integration and circulation of parts of a story through different channels (media, social media platforms, among others), understood as the different outlets where narratives develop, or as the Greek philosopher Aristotle quoted, in his rhetorical study and contemporary understanding of synergy, "the whole is greater than the sum of parts". This sequence, initially planned by a sender and appropriated by several individuals interacting with the story, aims to recontextualize and add value to the story [5].

As a result of the vast studies related to transmedia storytelling, a series of patterns have been identified: story, navigation, and instance. Story patterns focus on the relationship between the media and narrative (telling the story itself, being involved in or enhancing it). This means exploring the relationships between the different ways of 
telling a story (multiple media to tell several or a single story). Navigation concerns how individuals navigate through it, and how they select the channel (experience a story sequentially, through multiple options or combining it-linear, non-linear, cumulative, or connected). Additionally, instance relates to how the audience consumes the story (passively or actively-role-play, audience-centric, live event, artefact) [6]. In this sense, the purpose of transmedia storytelling is to create synergies and participatory experiences among audience to make sense of the stories [7].

While previous statements are a reasonable starting point, the potential of transmedia channels, texts, and tools empowering individuals may be missed. Indeed, communitycreated stories take advantage of the semiotic possibilities of digital platforms, creating dynamic, engaging and creative storytelling environments [8]. Narratological worlds involve increasingly sophisticated and expressive discourse that is adapted to human and technological realities. Thus, some authors have stressed the need to distinguish between "fiction" and "narrative". Fiction would be understood as the creation of worlds, and narratives as the process of organizing discourse. This means that all fiction is structured by a narrative, although narratives are not necessarily fictional [9]. In this way, we understand transmediation as a wider phenomenon of re-mediation, in which traditional and digital media establish several connections, often integrating narrative.

Transmedia storytelling, albeit a consolidated process, is currently adapting to digital cultures with great potential. Digital storytelling is not far removed from earlier storytelling forms, as both involve new criteria for analysis, such as audiovisual language. The use of visual and audio representations of language enables a reshaping of digital messages [10]. Therefore, audiovisual language provides additional meaningful reality-fiction performances. The final goal of this approach is to promote interaction between different perspectives to articulate and connect communities and stories.

This article considers audio and video as popular community storytelling forms and as effective avenues for transmedia storytelling. Technical resources that are available to storytellers on relevant social networking sites, such as YouTube, create new synergies and meanings around inspirational ideas [11]. In this context, fans are engaged to produce symbolism that is derived from the cultural industry's outputs to tell their own stories through growing creative performances [12].

While the transmedia perspective on fictional storytelling has been widely explored, few studies have addressed the phenomenon of music, which precedes this narratological process that was suggested by Stuart Sanders Smith. We find research on the spread of fiction through Star Trek music videos [5], transmedia storytelling in the Nier video game mentioning the soundtrack [13], the selective musical and transmedia analysis of The Beatles Anthology [14], the parodied fanvids of the Game of Thrones series [15], or the transmedia and musical stories about the video game Los Rios de Alice by Vetusta Morla [16]. These cases offer limited examples of research focusing on music from a transmedia perspective, despite the transmedia storytelling's solid presence in the literature.

This paper departs from a shared premise: music video as a transmedia spreadable form with an active participation in the co-creation of stories $[17,18]$. Although the relationship of music and digital platforms has been thoroughly researched from various perspectives [19-23], the present study advances a starting point and in-depth analysis of music videos as a transmedia vehicle for franchise content, as exemplified by the study of Disney covers on YouTube. The purpose of this research is to address this gap in the literature through a grounded theory analysis to provide a starting point allowing for the consolidation of the basis for the analysis of musical blockbusters in terms of storytelling and user-generated content.

\subsection{Disney's Transmedia Experience through Music}

There are few fictional productions that have received as much criticism and media attention as Disney's films. The fact is that discussing animated films and fandom requires a familiarity with industry leaders, such as Disney, Pixar, Studio Ghibli, among 
others [24]. The Walt Disney Company has become the largest audiovisual content producer in the world, monopolizing children's audiences. Authors have coined the concept media "Disneyization" to describe this phenomenon [25]. Disney manages all activities that are related to the exploitation of characters, licensed products, and fictional worlds [26]. Moreover, the company has its own Disney Consumer Products and Interactive Media platform, dedicated to the innovation and creation of digital experiences: video games, apps, books, toys, and shirts. In short, Disney is known as a transmedia brand itself [27].

Its relationship with music constitutes a cultural strategy that distinguishes the company. Its founder, Walt Disney, considered music to be a powerful art and mass culture resource, responsible for creating imaginaries that transcended people's diverse backgrounds, such as socioeconomic conditions, age, or country [28]. For this reason, today we can find great composers, orchestras, singers, and bands performing the popular musical compositions of his films [29]. In this landscape, animated films become especially remarkable, as their technical refinement and evolution in terms of quality have improved [30]. The interplay between sound and image is essential for the film, but also for the artist and the audience [31]. Starting with "Who's afraid of the big bad wolf?" and "Zip-adee-doo-dah", Disney's music and songs have been part of its identity and culture for generations [32,33].

Although Walt was neither a musician nor trained in the field, he acknowledged the significance of music in society, particularly in animated films targeted to families [29]. In this sense, the role of Disney's imagineers is remarkable. These are professionals in charge of creating a wide variety of musical narratives to surprise theme park guests, in order to experience fiction [34]. Disney understood that adding sound and music to the images could radically change the audience's perception. Thus, anodyne images could convey emotions [35]. The film Fantasia became Disney's iconic "Imagineering" example, where they merged science, creativity, and musical engineering [36]. It was an addition of meaning and emotion based on synaesthesia (fantasound), where music steered the animation. The film, which featured cinematographers and an orchestra, grossed more than ninety million dollars [37].

We consider that music has taken its own particular role in animated film. Thanks to industry icons, such as Disney, today we can no longer imagine a film without editing, script, photography, and, of course, soundtrack [38]. This research acknowledges Disney's extensive history in transmedia production and the significance attributed to music from the beginning. Therefore, we assume that analyzing the phenomenon of transmedia spread through this company's songs becomes essential in understanding the process into other fictional worlds. Specifically, across platforms that also emphasize the musical character of contemporary forms of creativity and content production: YouTube.

\subsection{Music and Covers on YouTube}

Similar to the ways in which music has impacted cultural industry companies, such as Disney, it has also played a significant role on the Internet and digital platforms. More concretely, audiovisual venues, such as YouTube, which has resulted in countless music videos created by fans from all over the world. Music fandom activity has joined creative diversification in a way that is unparalleled in human history [39].

Music has been a cornerstone of social interaction since the MTV era in the 1980s, where music videos are the most consumed content in today's video-sharing services [40,41]. The networked access to music and videos has influenced music reception cultures among users. As a consequence, music videos are now a significant digital model of production, distribution, and consumption [42].

In this context, there are several publications on musical behavior in social media. Studies that highlight the didactic use of video tutorials and informal online musical learning [43,44], or those focusing on musical exchange communities and virtual performances [45-47]. This environment encourages music video's popularity as a storytelling and promotional tool. YouTube is particularly noteworthy in this context. 
The platform, similar to Disney, has experienced great growth among audiences around the world, turning into a video-centered ecosystem of free-to-use content that supports music $[48,49]$. In fact, most of the content on YouTube involves music: from official record labels, such as Warner Music Sound, or multinational video hosting service and multi-channel network, such as VEVO-where participate various record labels-to cover songs, parodies, remixes, or mash-ups [50]. These user-generated contents, and especially covers, are extremely influential in the fictional universe, which makes them the quintessential channel for fan expression.

A cover music video on YouTube refers to a musical version that modifies and, in some cases, expands the original in many aspects (interpretative, instrumental, aesthetic...) [51]. The creation of cover versions leads to a sort of musical hierarchy that is based on non-professional routines and performance as entertainment addressed to mass audiences [52,53]. The relevance of this audiovisual product stems from the relationship between the musician and cultural prosumer. Today, this becomes more evident in a digital experience [54]. The Internet has provided amateur musicians a space for creating and sharing inter-creative (interactive and creative) works, leading to The Cover Age. In this context, the cover is undergoing "re" patterns, including repetition, retrieval, reincarnation, recycling, redesign, and reprocessing [55]. The link between music and image turns YouTube, among other pop platforms, such as TikTok, as suitable platforms for storytelling development and innovation [56], which will be analyzed in the following sections.

\section{Materials and Methods}

We followed a methodology integrating mixed methods and Grounded Theory in order to achieve the main objective [57]. Our aim was to apply specific and systematic methods of data collection and analysis in several stages of coding to understand the transmedia music phenomenon [58].

As illustrated in Figure 1, we conducted an initial iterative coding process in two qualitative stages: (1) deductive through pre-designed theoretical codes (analysis from general theories applied to individual units); and, (2) inductive (analysis of individual elements to understand a whole theory) through content analysis in the qualitative Atlas.ti 9 software (whose purpose is to transcribe, code, and interpret data through abstraction patterns). In this sense, memoing process serves to make conceptual leaps from raw data in order to explain a phenomenon. Subsequently, we carried out a third categorization to assess transmedia codes to identify the highest co-occurrence rates. In the last advanced coding stage, we performed a correlation analysis using a Chi-square statistical test to determine the relationship between transmedia and YouTube cover variables.

The research questions that guided this research were, as follows:

- $\quad$ RQ1: What characterizes transmedia music on YouTube cover versions of Disney songs?

- RQ2: What audiovisual language characterizes music videos that spread the narrative (music/image)?

\subsection{Sample}

We selected a sample based primarily on cover versions. The reason is that this type of adapted music video is one of the most common formats in content created by YouTube musicians, becoming extensively famous on the platform [55]. As we discussed before, the present study combines three emerging insights to understand the (trans)music networked culture: YouTube, Disney fandom, and cover songs [59].

We selected a sample comprised of English and Spanish covers in order to provide an expanded theoretical and international perspective. Videos were collected from YouTube through a simple random browser search, selecting a total of 300 videos. The criteria involved the formula: "Spanish/English title of the Disney animated film + cover" (filtered by "relevance"). 


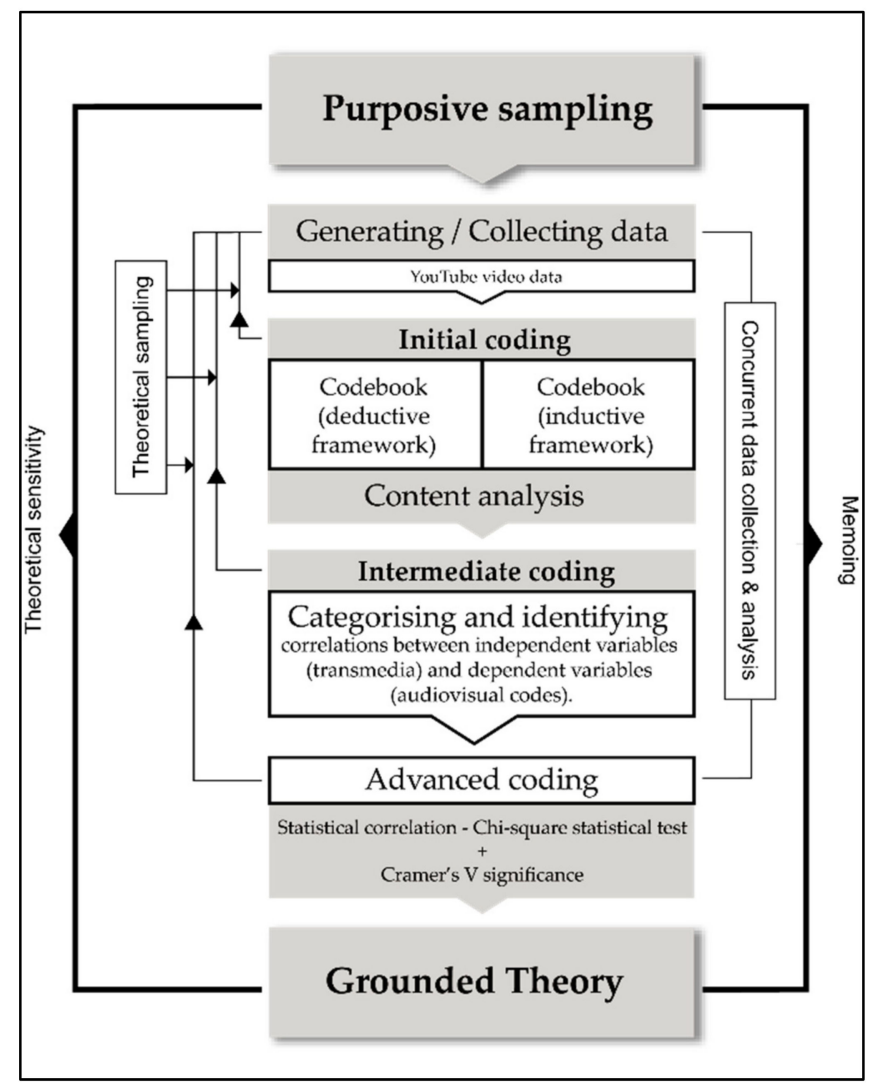

Figure 1. Methodological process through theoretical memoing.

We randomly selected 15 Disney animated films based on their chronological release dates in the film industry, collecting 10 Spanish covers and 10 English covers (Table 1).

Table 1. Simple random sample.

\begin{tabular}{cccc}
\hline Disney Film & Release Year & No. of Covers & Total \\
\hline The Little Mermaid & 1989 & 20 & \\
Beauty and the Beast & 1991 & 20 & \\
Aladdin & 1992 & 20 & \\
The Nightmare before Christmas & 1993 & 20 & \\
The Lion King & 1994 & 20 & 300 covers \\
Pocahontas & 1995 & 20 & of Disney \\
The Hunchback of Notre Dame & 1996 & 20 & animation \\
Hercules & 1997 & 20 & films \\
Mulan & 1998 & 20 & \\
Tarzan & 1999 & 20 & \\
Tangled & 2009 & 20 & \\
Frozen & 2010 & 20 & \\
Moana & 2013 & 20 & \\
Coco & 2016 & 20 & \\
\hline
\end{tabular}

\subsection{FirstStage: Deductive Codebook}

We focused on four studies on semiotic and content analysis about music videos and transmedia storytelling in order to develop a deductive, theoretically derived codebook [60-63].

We used a codebook that included audiovisual categories (content) and codes to evaluate how the story spreads (transmedia), according to Table 2. 
Table 2. Deductive codebook.

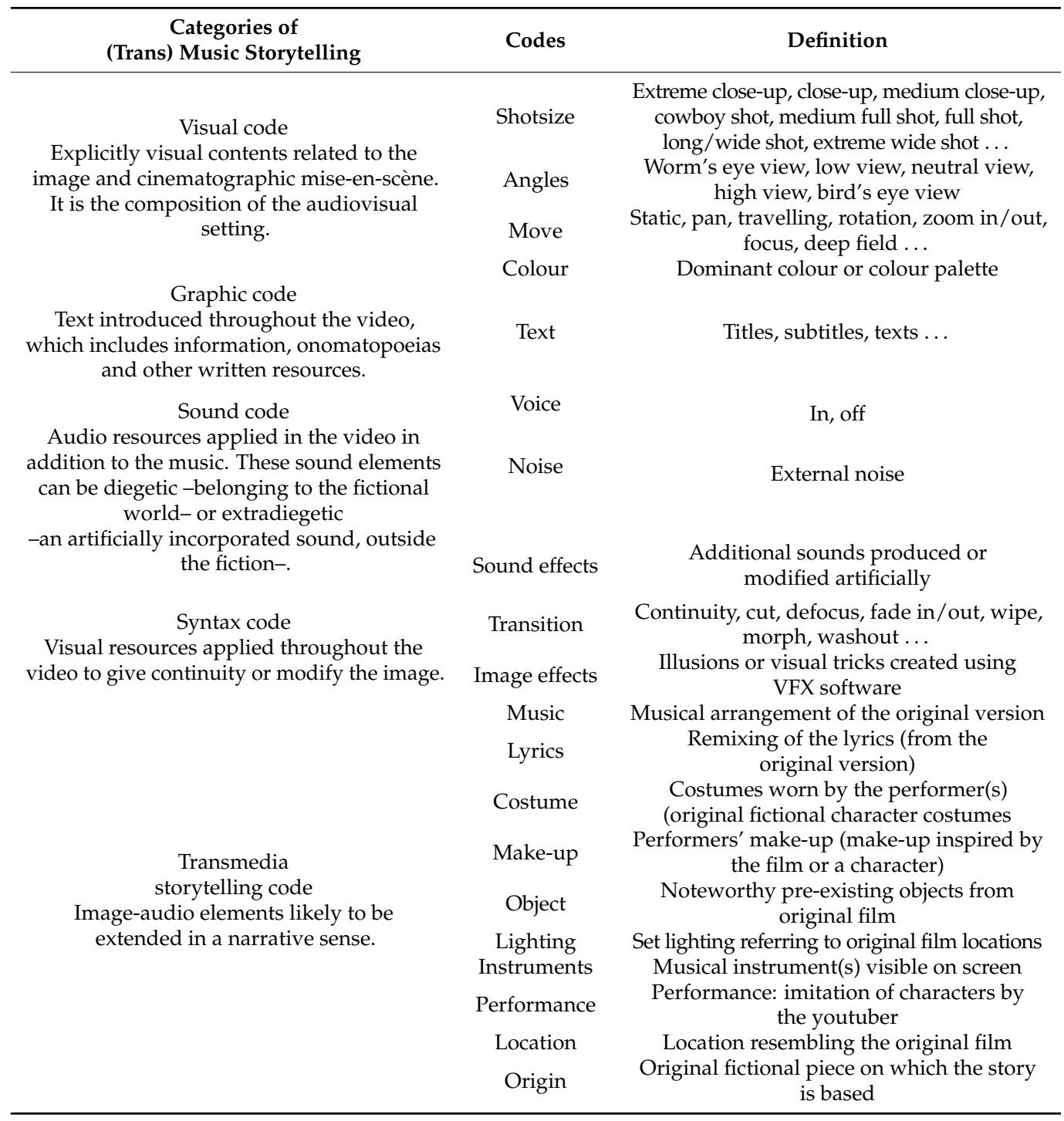

Thus, we formulated a codebook that consists of five categories and 20 codes. These were entered into the Atlas.ti 9 software, where the codes were distributed and processed in a first analysis that lasted four months (from October 2020 to January 2021).

\subsection{Second Stage within the Qualitative Process: Inductive Codebook}

After finishing this preliminary coding, we proceed with the inductive stage. In this case, we applied the saturation coding system [64]. This approach enabled the identification of codes that were repeated several times, which could be added to the previously defined categories, or used to create new ones.

We inserted the following codes to our initial research instrument: (1) "credits and comments" (performer's comments with credits on the video/platform channel/music); (2) Graphic code: "credits" (video/cover title, performer's name, or additional data regarding the video) and "logo" (the graphic mark, emblem, or symbol to promote and identify Disney's company); (3) Syntax code: "intro" (original introduction or presentation adapted from Disney's corporate teaser); (4) Transmedia storytelling code: "chroma key" (chroma key resource from film or audio-visual elements that are related to the movie) and "transition film scene" (clips and images from the original film). On the other hand, we added the categories and codes listed below: (5) Background codes: "headphones" and "microphone"; and, (6) Number of People codes: "one performer/musician", "two 
performers/musicians", and "more than two performers/musicians". In summary, seven categories and 31 codes were added.

\subsection{Third Stage: Integrating and Correlating Codes}

Once the codes were identified throughout the 300 Spanish-English videos of the Disney fandom world (1267 entries), we proceeded to integrate and relate the "audiovisual content" codes with the "transmedia" ones. Our purpose was to understand how the independent variable (transmedia) was related to the dependent variables (content), in order to connect the concepts. To this end, we applied a co-occurrence analysis in Atlas.ti. Through this system, we located the main correlations between codes, in order to determine the statistical associations via Chi-square test in SPSS v. 24.

\section{Results}

Once the coding process was finished, we conducted an analysis of code co-occurrences and correlations, using a mixed qualitative and quantitative approach. First of all, to obtain an overview of the code network, we entered the results from the content analysis into the Gephi 9.2 software. Data were filtered by the average path length and distance between centrality evidenced various co-occurrences within the network, which resulted in 31 nodes and 210 edges (Figure 2).

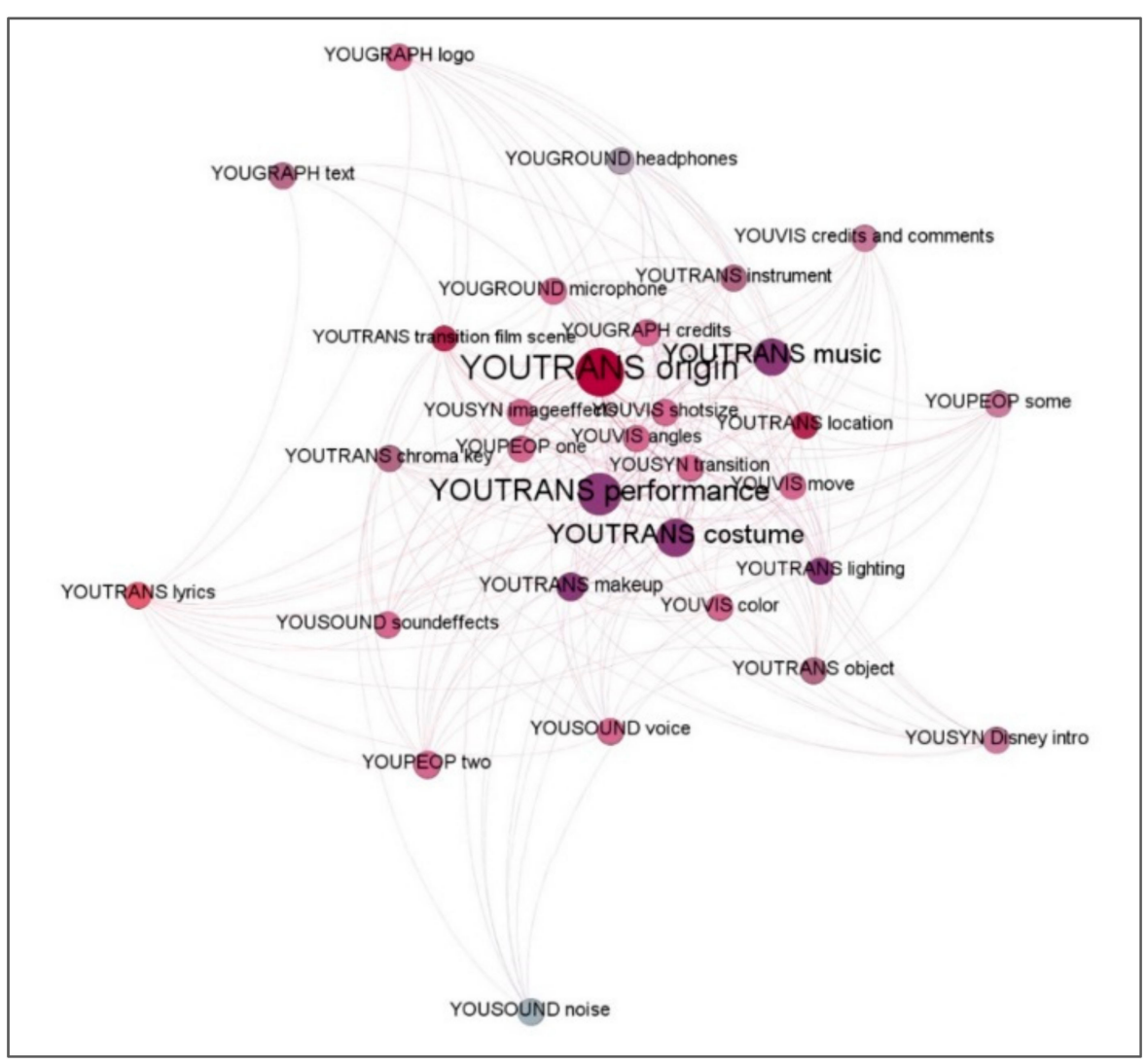

Figure 2. Network analysis of the transmedia music phenomenon.

Following this preliminary approach to the phenomenon, we noted that the code "origin" (original Disney song) had a high degree of centrality. This means that, as suggested in studies on transmedia storytelling [1,2,5,7], fictional narratives depart from a starting point. In this case, we found the "origin" code reflected as the central element of the network, from which the other elements involved in the story start. As a result, the transmedia code was highlighted in terms of "music", "performance", "costume", "location", among others. In this sense, we evaluated this general overview through co-occurrences of transmedia-content codes. 


\subsection{Trans(music) Storytelling Analysis of Co-Ocurrence}

\subsubsection{Music}

The code "music" refers a different instrumental arrangement that, in some cases, changed the musical genre when compared to the original song. "Music" presented a high correlation with the visual codes "shotsize" $(n=225, r=0.71)$ and "angles" $(n=225$, $r=0.71)$, also with syntax codes "transition" ( $n=150, r=0.51)$ and "image effects" ( $n=86$, $r=0.34)$, and within number of people codes, "one-person" ( $n=64, r=0.25)$, and "credits" $(n=113, r=0.40)$.

This was present in 121 videos. In this type of content, youtubers performed musical arrangements of the original song with a different melodic, rhythmic, or harmonic base, and post-processing of sound (Figure 3).

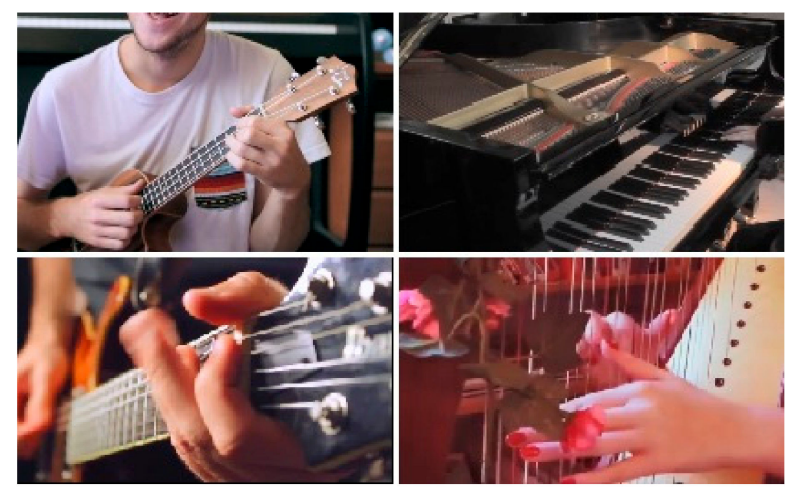

Figure 3. Disney song performances with musical instruments displayed visually.

Throughout the sample, we observed how the original piece was adapted to singleinstrument creations and entire musical genres. Particularly outstanding were the use of the piano, classical and electric guitar, drums, violin, ukulele, cello, violoncello, harp, saxophone, flute... Genres included heavy metal, pop, rock, garage rock, jazz, bachata, and folklore cover songs from the Disney franchise also stood out. In many cases, the performers combined one or several voices in post-production in order to create melodies, rhythms, harmonies... That is, complex single-person a cappella forms.

\subsubsection{Lyrics}

The code "Lyrics" involves changing the original words of the Disney song. When compared to the musical code, in this case we found fewer co-occurrences among the content variables. With a mean coefficient of 0.02 , the number of people code "one-person" $(n=5, r=0.02)$, and the syntax codes "image effects" $(n=6, r=0.03)$ and "transition" ( $n=5$, $r=0.02)$ are noteworthy. Only six cases appeared in the entire sample.

\subsubsection{Costume}

Throughout the analysis, we identified that the transmedia code "costume" was the one most commonly used by youtubers to spread Disney narratives. Often, they played the role of the character itself (top left frame and bottom right frame), or generated new stories with costumes based on the settings or movie events (top right frame and bottom left frame) (Figure 4).

The most relevant co-occurrences between transmedia and content variables were: within number of people codes "one-person" ( $n=103, r=0.37)$, within syntax codes, "image effects" ( $n=120, r=0.44)$, and "transition" $(n=166, r=0.50)$, within visual codes "colour" ( $n=72, r=0.35)$, "angles" $(n=184, r=0.45)$, "move" $(n=87, r=0.41)$, and "shotsize" $(n=186, r=0.45)$. In this sense, aesthetical aspects prevailed. We identified 176 costume codes. 


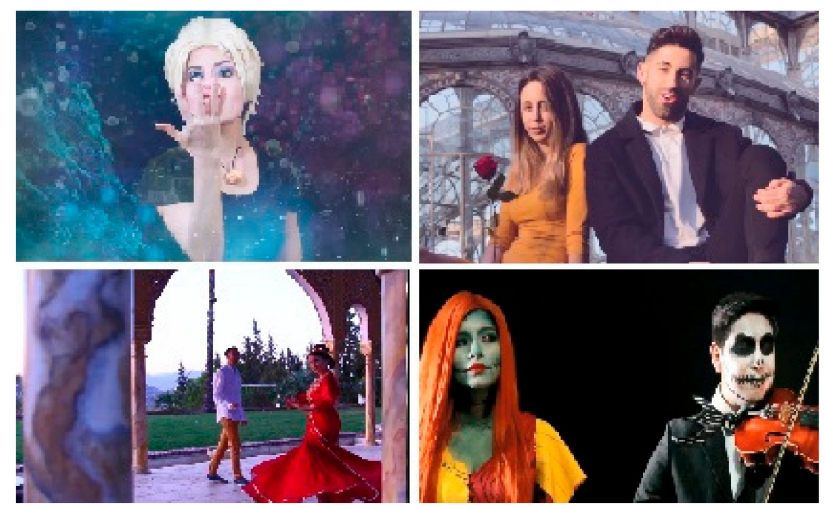

Figure 4. Film costume examples.

\subsubsection{Make-Up}

Make-up, alongside costume, constituted another of the most representative codes in our analysis. From 139 cases located, we identified maximum co-occurrences with "oneperson" ( $n=80, r=0.30)$, "image effects" $(n=89, r=0.33)$, and "transition" codes $(n=112$, $r=0.32)$, as well as "angles" $(n=143, r=0.34)$, "colour" $(n=54, r=0.29)$, "move" $(n=55$, $r=0.26)$, and "shotsize" $(n=144, r=0.34)$. In this case, aesthetics in transmedia musical storytelling stood out again.

The make-up code was applied as part of the characters' portrayal by the youtubers. Nevertheless, in many cases, this resource was used to refer to fictional universes (Figure 5). For instance, the song "La Llorona" sung by "Catrina" (Dapper Skeleton) from the movie Coco, or a zombie, wolfman, and demon singing "This is Halloween" from the The Nightmare before Christmas.
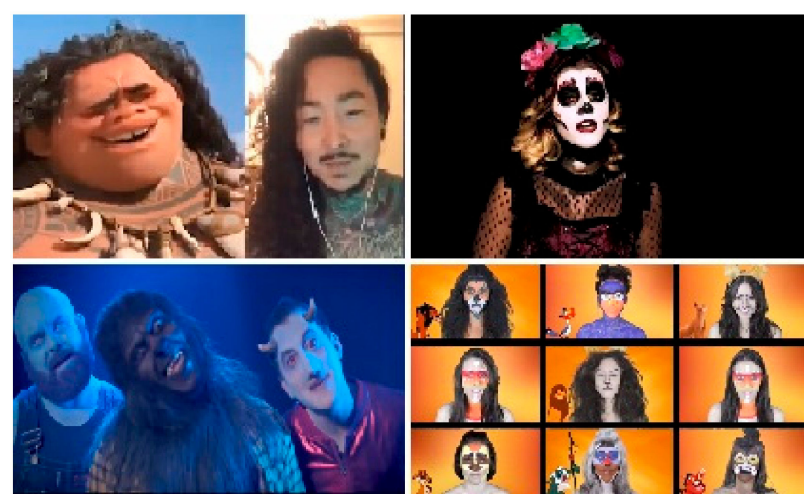

Figure 5. Make-up examples to expand youtubers' musical stories.

\subsubsection{Object}

The "object" code embodies all of those living or inanimate items that remind us of the original film. Repeated examples can be seen in Beauty and the Beast (the rose), The Little Mermaid (seashells), Frozen (the nose of Olaf character), Aladdin (the magic lamp), among others (Figure 6).

We identified 63 objects in the sample. Co-occurrences with "transition" ( $n=63$, $r=0.20)$, "angles" $(n=68, r=0.16)$, and "shotsize" $(n=68, r=0.16)$ were highlighted. This could be due to the importance of emphasizing objects from the original story in the video, by editing through extreme close-ups that amplify the original story. 

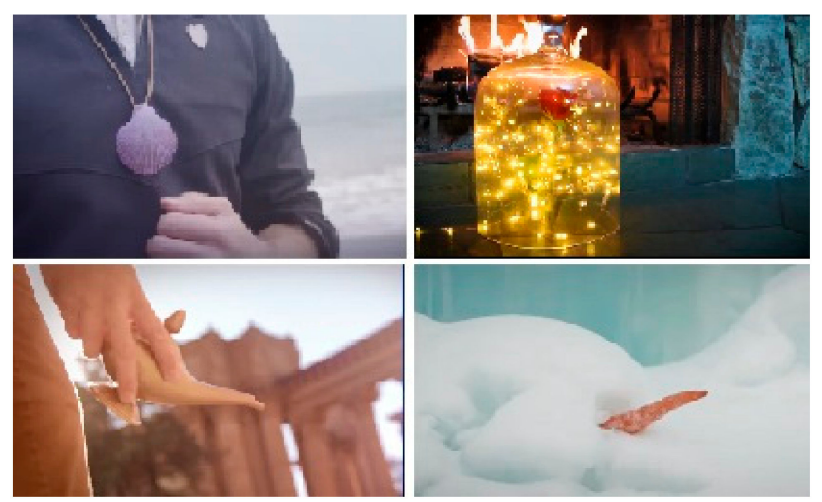

Figure 6. Example of fictional objects highlighted in the videos.

\subsubsection{Lighting}

The "lighting" code was found in 111 covers. A resource adopted in different sets to take the audience to scenes from the original film. Figure 7 illustrates lighting in songs, such as: "Arabian Nights" from Aladdin and "I won't say (I'm in love)" from Hercules with a night scene, or "Circle of life" from The Lion King and "I see the light" from Tangled with a daylight scene.
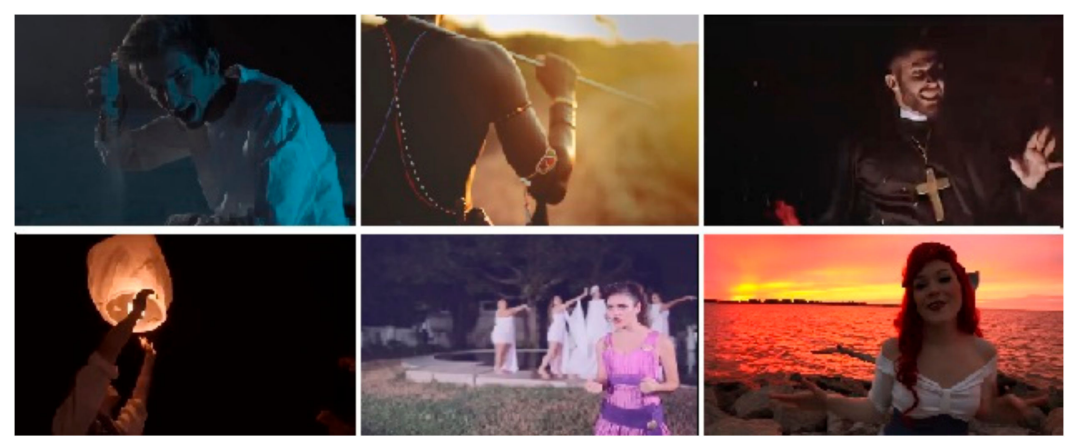

Figure 7. Film lighting examples.

Light is also used in these music videos to emphasize the character's identity (hero $=$ lightness $/$ villain $=$ darkness). For example, two examples of this story-lighting trend are shown in the two frames on the right of Figure 6: at the top in dark light, we see the villain from The Hunchback of Notre Dame, Judge Claude Frollo, in the song "Hellfire", while, at the bottom image, we find Ariel from The Little Mermaid with a sunset reflecting the loving nature of the song "Kiss the girl".

We found seven co-occurrences coded, as follows: number of people code "oneperson" ( $n=55, r=0.21)$; syntax codes "image effects" $(n=68, r=0.26)$ and "transition" $(n=109, r=0.34)$; visual codes "angles" $(n=120, r=0.29)$, "colour" $(n=66, r=0.46)$, "move" $(n=81, r=0.52)$, and "shotsize" $(n=120, r=0.29)$.

\subsubsection{Instruments}

Similar to the previous musical code, the instruments were visually present in many covers. Although the frequency was lower $(n=83)$, co-occurrences with visual and syntax aspects are becoming more prominent. This included syntax codes "image effects" $(n=42$, $r=0.16)$ and "transition" ( $(n=78, r=0.24)$ (syntax code); and, visual codes "move" $(n=41$, $r=0.25)$ and "shotsize" $(n=100, r=0.25)$. The instruments, as with objects, were part of the performance, contributing to the narrative value of the videos.

Figure 8 shows that the instruments suited the musical personality of the character/song. The frame on the upper left belongs to the villain's song "Friends on the other side" from The Princess and the Frog (electric guitar), and the one on the right to Aladdin's genie in "Friends like me" (trumpet). On the lower left we find a screenshot of "A whole 
new world" from Aladdin with different instruments (violin, violoncello, and piano), and to the right "Sally's song" with piano in The Nightmare before Christmas. These examples illustrate the musical code (the genre), whereas their usage fits the role of the characters. In other words, when an electric guitar appears in a heavy metal composition, it fits Facilier's villainous character; jazzy trumpets to Aladdin's genius; or, a single piano for Sally's lament.
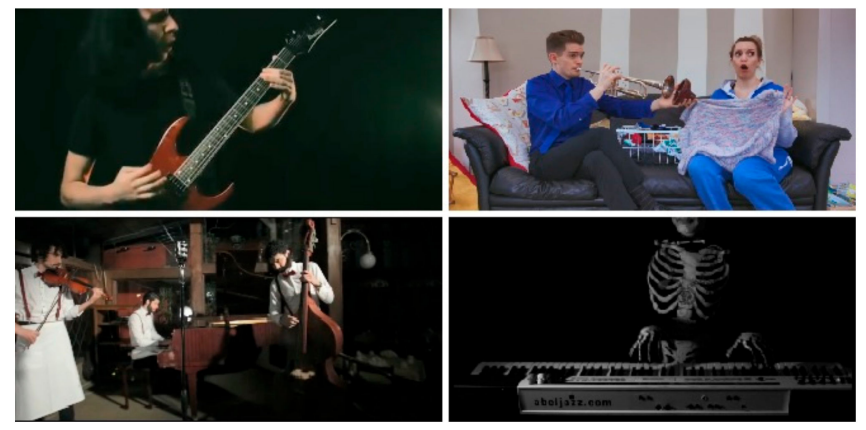

Figure 8. Examples of instruments supporting the song.

\subsubsection{Performance}

The "performance" code was particularly relevant throughout the sample $(n=275)$. The performance style of the youtubers emerged, even in cases where other transmedia codes were not visible. In this case, we found a significant sample of fans' expression in Disney films. Youtubers played the role of the characters or were involved in the universe of the story. In Figure 9, we noted the performance of Belle and the Beast (top left frame) in "Beauty and the Beast", Pocahontas and John Smith (top right) in "Colors of the wind", Li Shang (bottom left) in "I'll make a man out of you", and Moana (bottom right) in "How far I'll go".
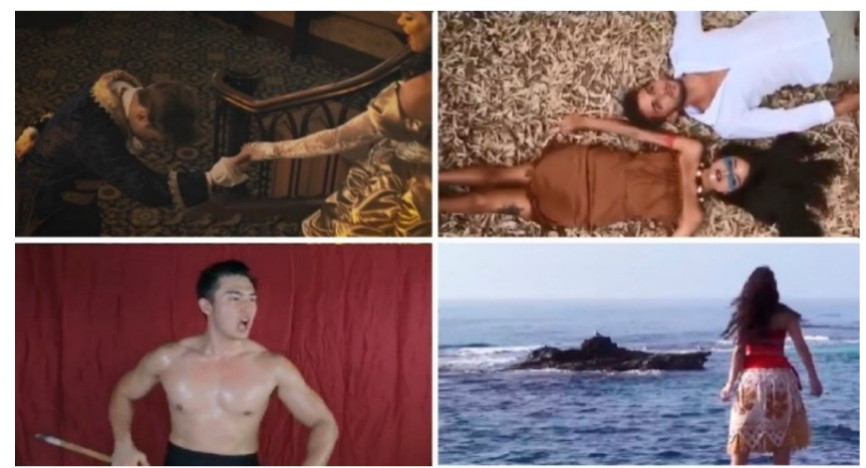

Figure 9. Example of youtuber performance frames.

The content codes that were directly related to the transmedia variable were graphic code "credits" ( $n=109, r=0.25)$; background code "microphone" $(n=96, r=0.29)$; number of people codes "one-person" ( $n=155, r=0.48)$ and "two-person" $(n=69, r=0.25)$; sound codes "sound effects" $(n=66, r=0.23)$ and "voice" $(n=54, r=0.19)$; syntax codes "image effects" ( $n=171, r=0.53)$ and "transition" $(n=212, r=0.55)$; and, visual codes "angles" ( $n=292, r=0.73)$, "colour" $(n=88, r=0.31)$, "move" $(n=109, r=0.37)$, and "shotsize" $(n=292, r=0.72)$. The youtuber musician's performance depended on the visual and sound settings. For this reason, the sound and visual effects are especially relevant.

\subsubsection{Location}

"Location" was a code mainly related to aesthetic categories $(n=117)$. Noteworthy co-occurrences were involved syntax codes "image effects" $(n=62, r=0.23)$ and "transition" 
codes $(n=115, r=0.35)$; as well as visual codes "angles" $(n=126, r=0.31)$, "colour" $(n=51$, $r=0.31)$, "move" ( $n=85, r=0.54)$, and "shotsize" $(n=126, r=0.30)$.

As shown in Figure 10, we noticed two trends: (1) locations that remind us of the film's environments, even if they were not exactly the same; and, (2) locations where the set is completely changed to confer additional value to the story. In the first case (upper images), we found Ariel from The Little Mermaid on the boat singing the song "Kiss the girl" and Santa Claus from The Nightmare Before Christmas performing "Oogie Boogie's Song". In the second one (images below), we found the youtuber standing in a children's pool spraying water on him, surrounded by a garden, and performing the song "Under the sea" from The Little Mermaid, and another youtuber singing "When will my life begin?" in real life (in a confined pandemic situation) resembling Disney's Tangled. Moreover, we also found the youtuber's interest in parodying the context. Thus, the parallelism between every day or current footage with film performances suggested the significant interest for adding humorous content to the musical clip. Accordingly, this category could be considered to be a potential code for analysis in future research.

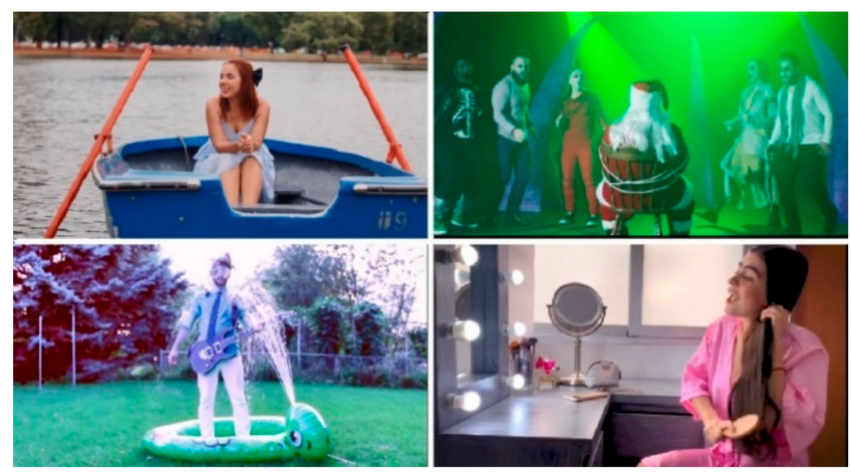

Figure 10. Examples of film and additional universe locations.

\subsubsection{Transition Film Scene and Chroma Key}

The codes "transition film scene" and "chroma key", which were added in the second stage analysis due to their frequency in the covers, were analyzed together, due to their aesthetic nature. These two codes were combined, since, in many cases (Figure 11), the chroma key was used to introduce original frames from the film.

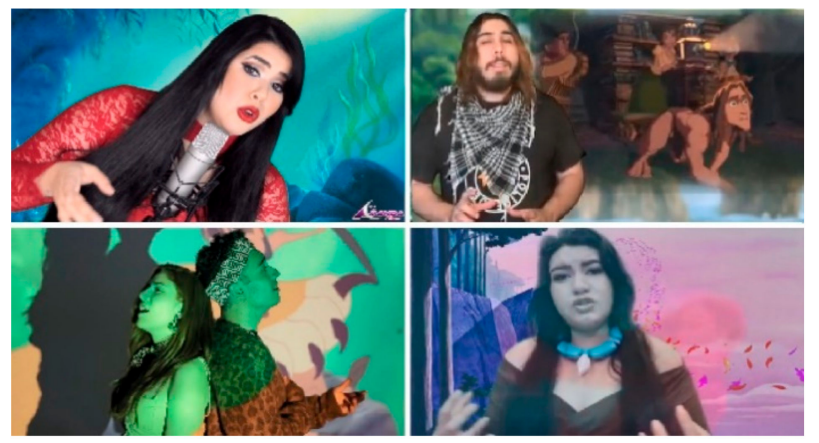

Figure 11. Combined examples of chroma key and transition film scene.

For videos involving a chroma key, the following codes were relevant: "image effects" ( $n=61, r=0.26)$, "transition" ( $n=58, r=0.17)$, "angles" $(n=74, r=0.18)$, and "shotsize" ( $n=75, r=0.18)$; and, for film transitions: "image effects" $(n=80, r=0.29)$, "transition" ( $n=109, r=0.31)$, "angles" $(n=114, r=0.26)$, "shotsize" $(n=120, r=27)$, as well as the "headphones" ( $n=66, r=0.30)$ and "one-person" codes $(n=70, r=0.26)$. Both content codes focused on the visual features. Furthermore, transitions were inserted in scenes that were not set in the same location as the original film (transmedia code "location"). This means that it was limited to the youtuber's recording site (his bedroom, a recording 
studio, etc.). This is why they incorporated background equipment, such as headphones and microphones.

\subsubsection{Origin}

The code "origin" refers to the recognizability of the original song from the film. Because the sample was comprised of cover versions of Disney animated films, we found this code in all of the videos. Thus, its co-occurrence with content codes was not considered to be significant throughout the analysis. Nevertheless, this code was taken into account to identify the songs, as well as for future research on transmedia music.

\subsection{Trans(music) Storytelling Correlation Analysis}

We carried out a Chi-square test in order to establish the effect of the content characteristics coded on the dissemination of transmedia cover versions. The objective of this analysis was to determine the significance of the correlation between the content of the cover and transmedia storytelling.

In this sense, we found that $\chi^{2}=628.96, p=0.001,1-\beta=1 ., W=3.92, g l=198$. The effect size $(1-\beta)$ and statistical power $(W)$ exceeded the standards $(W=<0.50)$, with a statistical significance of 0.001 . That is, the relationship is not random and it shows a correlation between the cover version and transmedia storytelling. The test proved significant differences between the transmedia-content groups, showing high association values that can be extrapolated from the sample to a broader population. Therefore, fandommusical content developed by youtubers spreads the Disney franchise narratives.

\section{Discussion and Conclusions}

Audiovisual language codes and narrative analysis allowed for us to explore the concept of transmedia music. The in-depth and detailed analysis process made it possible to build a synergy among the parts that constitute the Disney fiction cover songs in order to assemble a theoretical whole $[4,5,7]$. Our aim was to make sense of the vast fandom-musical production around imaginary worlds: from Disney animated films to video games, series, apps, and comics $[5,13-16]$. We intended to address a practice that is increasingly popular on social media, where new platforms are joining the audiovisual presence that YouTube consolidated. For example, Instagram TV/stories or TikTok videos [65].

Based on the first analysis, we found that, understandably, the transmedia component $[58,59]$ prevailed over the audio-visual content codes $[60,61]$. We are faced with a phenomenon that emphasizes the original piece (the pre-existing musical composition that is produced by the cultural industry), spreading through codes related to creative configurations, such as the use of instruments, costumes, lights, performance, and make-up. We provide answers to the research questions in order to understand these links.

\subsection{RQ1: What Characterises Transmedia Music on YouTube Cover Music Videos of Disney Songs?}

For the first question guiding the analysis, we found a series of aspects that revealed the spread of Disney's narratives through cover music videos on the platform. We drew from the three patterns of transmedia storytelling in order to identify the ways in which audiovisual creative strategies were executed in youtubers' productions: story, navigation, and instance [6].

The story pattern, which connects media and narrative (telling the story, being involved in the story, or enhancing the story), was present in most of the videos analyzed. The youtubers, as we showed in the results, were part of the story, playing the main character (or the secondary characters, when a capella arrangements made by one person in post-production were present). Thus, in those productions where the transmedia aspects matched the audiovisual aesthetics, the performer was immersed in the story. In some cases, the youtuber appeared in the space-time of the imaginary world of Disney [38]. As an example, we found covers in which the singer/musician was the main character, imitating the original character (e.g., telling the story dressed like Megara from Hercules 
and mimicking her attitude). Covers in which the singer/musician was placed within the fictional universe, even though he/she was not part of it (telling the story as a singer dressed as a sailor on the seashore to sing the song from The Little Mermaid). Or enhance the story with additional meaning (the very essence of transmedia), comparing the qualities of Aladdin's genie to the skills of new parents whose friendship is unique [5]. In this pattern, the "performance" code was noteworthy, being one of the most common and significant in the analysis.

Subsequently, we examined the navigational pattern, referring to the ways in which these youtubers participated in the story. In these cases, they made use of audiovisual language resources based on more than the character's performance. As we noted, lighting techniques, make-up, costumes, special effects, and image effects all played an influential role in the way in which they portrayed the story. Many youtubers preferred to appear in front of a microphone and sing the song or play one or more instruments (without significant emphasis on storytelling), and others favored dressing up as characters from the original film or in costumes from the film's fictional universe. Many of them often used lighting to enhance their musical performance. Taking part in daytime or nighttime segments of the story, bringing the lyrics of the song to life through locations that evoked the film, or adding objects that reminded the original environments present in the film were frequent patterns. Consequently, these practices are also related to the manner in which youtubers are active consumers of the story, becoming fan-imagineers [34].

In addition to these considerations, we found a significant relationship between these phenomena through statistical correlation analysis, which is especially transferable to other scenarios (that are not linked to YouTube or Disney). In short, the codes applied show a prevalence of full narrative dissemination in a large and diversified sample.

\subsection{RQ2: What Audiovisual Language Characterizes Music Videos That Spread the Narrative (Music/Image)?}

Aesthetic and musical aspects were both emphasized in the music videos analyzed, as we mentioned throughout the analysis. That is, we did not identify a prevalence of one language over each other. These videos are characterized by the synergy of both resources to spread the story [3,4].

Whereas, the lyrics of the song were hardly changed in the corpus analyzed, the musical basis was particularly influential. In other words, the musical genre, together with the special effects, transitions, lighting, color, angles, camera moves and shotsize, and performance, were essential in providing value and meaningfulness to the performance. As we discussed, it was very common to employ heavy metal genres for the villains, or pop/classical themes for the heroes. It was also quite typical to use bright and warm-colored scenes for happy and joyful stories, or dark and dull scenes for sad or dark stories. The interaction of content and storytelling codes resulted in a specific language of transmedia music that we consider in the next section [58].

\section{Future Studies in (Trans)Music Analysis}

The present study explores a well-established transmedia storytelling concept [5-8], but, so far, barely documented (trans)music practice in existing literature. Even though Stuart Sanders introduced the concept [2], previous research on the spread of fictional storytelling through music had not focused on human practices. In other terms, this experience enhances the historical and human value of storytelling over the mere mix of musical instruments [8].

This phenomenon is characterized by a specific audiovisual language that develops on social media: image and sound effects, illumination, texts, performance, and others. Transmedia music suggests a new sustainable practice that disseminates fictional worlds and imaginaries [13-16,41] through audio-visual strategies that are adjusted to the digital platform (in our case, YouTube). The sustainability aspect of the phenomenon is essential in understanding this musical practice in social media. In this sense, we understand sustainability as the development of communication networks that address the human cultural 
and media interrelation demands. In other words, the new generations participate and decide how to tell stories in the digital sphere, which strengthens a social and sustainable paradigm over time. Therefore, a combined structure stands out between the content-story and the performer-story through a media cluster, co-constructing new stories that take music as the origin of new and continuous performances [17,18].

To sum up, we understand transmedia music as a sustainable phenomenon that stems from the cultural industry and developing into human-story interaction patterns on social media. A performance where the musical background determines how a story with new meanings are told. Accordingly, we realize that, outside the thresholds of fandom itself, this storytelling strategies can also be present in other contexts where fiction and reality are portrayed. As a result, we propose a new paradigm that is based on the rise and diversity of social media. Transmedia music may provide an open framework for specific studies on the musical spread on TikTok, IGTV, Spotify Storyline, among others.

Author Contributions: Conceptualization, A.V.-V.; methodology, A.V.-V.; software, A.V.-V.; validation, A.V.-V. and P.C.-P.; formal analysis, A.V.-V.; investigation, A.V.-V.; resources, A.V.-V.; data curation, A.V.-V.; writing-original draft preparation, A.V.-V.; writing—review and editing, A.V.-V., I.A. and P.C.-P.; visualization, A.V.-V., I.A. and P.C.-P.; supervision, I.A. and P.C.-P.; project administration, I.A.; funding acquisition, I.A. All authors have read and agreed to the published version of the manuscript.

Funding: This work was supported by "Alfamed" (Euro-American Research Network), under Grant $\mathrm{R}+\mathrm{D}+\mathrm{I}$ Project (2019-2021), entitled "Youtubers and Intagrammers: Media competence in emerging prosumers", with code RTI2018-093303-B-I00, financed by the Spanish Ministry of Science, Innovation and Universities and the European Regional Development Fund (ERDF), and the R + D-i Project (2020-2022), entitled "Instagrammers and youtubers for the transmedia empowerment of Andalusian citizens. The media competence of instatubers", with code P18-RT-756, financed by the Andalusian Regional Government in the 2018 call (Andalusian Research, Development and Innovation Plan, 2020) and the European Regional Development Fund (ERDF).

Institutional Review Board Statement: Not applicable.

Informed Consent Statement: Not applicable.

Data Availability Statement: The study does not report any data.

Conflicts of Interest: The authors declare no conflict of interest.

\section{References}

1. Dusi, N.; Ferretti, I.; Furini, M. A transmedia storytelling system to transform recorded film memories into visual history. Entertain. Comput. 2017, 21, 65-75. [CrossRef]

2. Atarama-Rojas, T.; Menacho-Girón, N. Narrativa transmedia y mundos transmediales: Una propuesta metodológca para el análisis de un ecosistema mediático, caso Civil War. Rev. Comun. 2018, 17, 34-50. [CrossRef]

3. Kinder, M. Playing with Power in Movies, Television, and Video Games: From Muppet Babies to Teenage Mutant Ninja Turtles, 1st ed.; University of California Press: Los Angeles, CA, USA, 1991.

4. Jenkins, H. Convergence Culture: Where Old and New Media Collide; NYU Press: New York, NY, USA, 2006; pp. 1-368.

5. Jenkins, H. Transmedia storytelling and entertainment: An annotated syllabus. Continuum 2010, 24, 943-958. [CrossRef]

6. Javanshir, R.; Carroll, B.; Millard, D. Structural patterns for transmedia storytelling. PLoS ONE 2020, 15, e0225910. [CrossRef]

7. Buehring, J.; Vittachi, N. Transmedia storytelling: Addressing futures communication challenges with video animation. J. Future Stud. 2020, 25, 65-78.

8. Hovious, A.; Shinas, V.H.; Harper, I. The compelling nature of transmedia storytelling: Empowering twenty first-century readers and writers through multimodality. Technol. Knowl. Learn. 2020, in press. [CrossRef]

9. Mittermayer, T.; Capanema, L.X.L. Transfictionality and transmedia storytelling: A conceptual distinction. Lect. Notes Comput. Sci. 2019, 11566, 550-558.

10. Jauregui-Caballero, A.; Ortega-Ponce, C. Transmedia storytelling in the social appropriation of knowledge. Rev. Latina Comun. Soc. 2020, 77, 357-371.

11. Podara, A.; Giomelakis, D.; Nicolaou, C.; Matsiola, M.; Kotsakis, R. Digital storytelling in cultural heritage: Audience engagement in the interactive documentary new life. Sustainability 2021, 13, 1193. [CrossRef]

12. Webster, L. Marvel, Star Wars and the risk of being a hero: Social responsibilities for transmedia storytellers in the age of collective journey. Cult. Sci. 2021, 12, 59-67. [CrossRef] 
13. Riera, P. Narrativa, música y transmedia en Nier: Hacia una nueva obra de arte total. Caracteres 2013, 2, $169-186$.

14. Rueda, J.; Galán, E. Historias en el universo transmedia. El proyecto The Beatles Anthology. Comun. Soc. 2013, 19, 181-212.

15. Vizcaíno-Verdú, A.; Sánchez-Olmos, C. La música y las narraciones transmedia: Estudio de caso del 'Main Title' de la serie Juego de Tronos. In Más Allá de la Pantalla. Música, Sonido e Imagen, 1st ed.; Encabo, E., Ed.; Elpoblet Ediciones: Sabadell, Spain, 2018; pp. 169-204.

16. Sánchez-Olmos, C.; Viñuela, E. Transmedia storytelling, music and videogames: The case of Los Rios de Alice by Vetusta Morla and Delirium Studios. Icono 14 2019, 17, 60-82. [CrossRef]

17. Scolari, C.A. Transmedia storytelling: New ways of communicating in the digital age. In Anuario AC/E de Cultura Digital, 1st ed.; Celaya, J., Ed.; Acción Cultural Española: Madrid, Spain, 2014; pp. 68-79.

18. Nuttall, E. Fiction of the Internet: From intermediality to transmedia storytelling in 21st-Century novels. Mod. Lang. Rev. 2020, $115,914-915$.

19. Baym, N.C. Playing to the Crowd: Musicians, Audiences, and the Intimate Work of Connection; NYU Press: New York, NY, USA, 2018; pp. 1-253.

20. Gamble, S. How Music Empowers. Listening to Modern Rap and Metal, 1st ed.; Routledge: New York, NY, USA, $2021 ;$ pp. 1-173.

21. Jaramillo-Dent, D.; Vizcaíno-Verdú, A.; De-Casas-Moreno, P.; Baldallo-González, C. Instagramming. Temas, Tópicos y Tendencias; Editorial Octaedro: Barcelona, Spain, 2020; pp. 1-150.

22. Kidd, E. Using digital music production as a culture catalyst. In Cultivating Entrepreneurial Changemakers through Digital Media Education; Byrd, L., Ed.; IGI Global: Hershey, PA, USA, 2021; pp. 122-139.

23. Rambarran, S. Virtual Music: Sound, Music, and Image in the Digital Era; Bloomsbury Academic: London, UK; pp. 1-248.

24. Marín-Díaz, V.; Solís, C. Los valores transmitidos por las mujeres de las películas Disney. Rev. CS 2017, 23, 37-55. [CrossRef]

25. Griffin, M.; Learmonth, M.; Piper, N. Organizational readiness: Culturally mediated learning through Disney animation. Acad. Manag. Learn. Educ. 2018, 17, 4-23. [CrossRef]

26. Freeman, M. A world of Disney: Building a transmedia storyworld for Mickey and his friends. In World Building: Transmedia, Fans, Industries, 1st ed.; Boni, M., Ed.; Amsterdam University: Amsterdam, The Netherlands, 2017; pp. 93-108.

27. Ferguson, K. Digital surrealism: Visualizing Walt Disney Animation Studios. Digit. Humanit. Quaterly 2017, 11, 1-30.

28. Armstrong, R. Time to face the music: Musical colonization and appropriation in Disney's Moana. Soc. Sci. 2018, 7, 113. [CrossRef]

29. Tietyen, D. The Musical World of Walt Disney, 1st ed.; Hal Leonard: Winona, MN, USA, 1990.

30. Montiel, M.K. Music in Disney's animated features: Snow White and the Seven Dwarfs to The Jungle Book. Pop. Music Soc. 2018, 41, 339-341. [CrossRef]

31. Lazarescu-Thois, L. From sync to surround: Walt Disney and its contribution to the aesthetics of music in animation. New Soundtrack 2018, 8, 61-72. [CrossRef]

32. Filipczak, D. Made to connive: Revisioning Cinderella in a music video. From Disney to Arthur Pirozkhov: A case study. Text Matters J. Lit. Theory Cult. 2020, 10, 67-78. [CrossRef]

33. Vuong, K. Intercultural music in media: Representations of Chinese music history and culture within Korra and Mulan. Spectrum 2020, 6, 1-10. [CrossRef]

34. Camp, G. Mickey Mouse Muzak: Shaping experience musically at Walt Disney World. J. Soc. Am. Music 2017, 11, 53-69. [CrossRef]

35. Carson, C. 'Whole new worlds': Music and the Disney theme park experience. Ethnomusicol. Forum 2006, 13, 228-235. [CrossRef]

36. Wasko, J. Understanding Disney. The Manufacture of Fantasy, 2nd ed.; Polity Press: Cambridge, MA, USA, $2001 ;$ pp. 1-336.

37. Clague, M. Playing in toon: Walt Disney's Fantasia (1940) and the Imagineering of classical music. Am. Music 2015, 22, 91-109. [CrossRef]

38. Hodge, M. Disney 'world': The westernization of world music in EPCOT's illumi nations: Reflections of earth. Soc. Sci. 2018, 7, 136. [CrossRef]

39. Macchiarella, I. Making music in the time of YouTube. Introduction. Philomusica Online 2017, 16, 1-11.

40. Vernallis, C. Unruly Media: YouTube, Music Video, and the New Digital Cinema, 1st ed.; OAP: New York, USA, 2013.

41. Baños-González, M.; Tiralaso, H.C.; Fernández, M.R. The broadcast of the music video on YouTube. Analysis of the viral capacity of the video clip. Rev. Lat. Comun. Soc. 2020, 77, 117-141.

42. Werner, A. YouTube and music video streaming participation, intermediation and spreadability. Stream. Music Pract. Media Cult. 2018, 1, 128-144.

43. Cayari, C. Connecting music education and virtual performance practices from YouTube. Music Educ. Res. 2018, 20, 360-376. [CrossRef]

44. Smith, R.; Secoy, J. Exploring the music identity development of elementary education majors using ukulele and YouTube. J. Music Teach. Educ. 2019, 29, 71-85. [CrossRef]

45. Loepthien, T.; Leipold, B. Flow in music performance and music-listening: Differences in intensity, predictors, and the relationship between flow and subjective well-being. Psychol. Music 2021, in press. [CrossRef]

46. Mohan, A.; Thomas, E. Effect of background music and the cultural preference to music on adolescents' task performance. Int. J. Adolesc. Youth 2020, 25, 562-573. Available online: https://www.tandfonline.com/doi/full/10.1080/02673843.2019.1689368?tab= permissions\&scroll=top (accessed on 13 February 2021). 
47. Pedrero-Esteban, L.M.; Barrios-Rubio, A.; Medina-Ávila, V. Teenagers, smartphones and digitl audio consumption in the age of Spotify. Comunicar 2019, 60, 103-112. [CrossRef]

48. Márquez, I. Nuevas practices de creación, distribución, consumo y sociabilidad musical. La youtubificación de la música. Telos 2017, 106, 1-9.

49. Marone, V.; Rodríguez, R.C. ‘What's so awesome with YouTube': Learning music with social media celebrities. Online J. Commun. Media Technol. 2019, 9, e201928. [CrossRef]

50. Park, J.; Park, J.; Park, J. The effects of user engagements for user and company generated videos on music sales: Empirical evidence from YouTube. Front. Psychol. 2018, 9, 1880. [CrossRef]

51. Dlaske, K. Music video covers, minoritised languages, and affective investments in the space of YouTube. Lang. Soc. 2017, 46, 451-475. [CrossRef]

52. Scarborough, R.C. Making it in a cover music scene: Negotiating artistic identities in a 'Kmart-Level Market'. Sociol. Inq. 2017, 87, 153-178. [CrossRef]

53. Wang, Y.; Inguva, S.; Adsumilli, B. YouTube UGC dataset for video compression research. In Proceedings of the IEEE 21st International Workshop on Multimedia Signal Processing, Kuala Lumpur, Malaysia, 27-29 September 2019; Institute of Eletrical and Electronics Engineers Inc.: Kuala Lumpur, Malaysia, 2019; p. 8901772.

54. Diaz-Gasca, S. Super Smash covers! Performance and audience engagement in Australian videogame music cover bands. Perfect Beat 2018, 19, 51-67. [CrossRef]

55. Vizcaíno-Verdú, A.; Contreras-Pulido, P. I am a youtuber musician! Construction of artistic identity through covers and fiction. The case of violinists Taylor Davis and Lindsey Stirling. Rev. Mediterránea Comun. 2020, 11, 25-36. [CrossRef]

56. Zhao, J.; Chen, C.; Zhao, L. The spread characteristics of music videos relating to COVID-19 in China online video platforms. Int. J. Commun. Soc. 2020, 2, 1-11. [CrossRef]

57. Strauss, A.; Corbin, J. Bases de la Investigación Cualitativa. Técnicas y Procedimientos para Desarrollar la Teoría Fundamentada, 2nd ed.; Editorial Universidad de Antioquia: Medellin, Colombia, 2002; pp. 1-297.

58. Chun-Tie, Y.; Birks, M.; Francis, K. Grounded theory research: A design framework for novice researchers. SAGE Open Med. 2019, 7, 1-8. [CrossRef] [PubMed]

59. Jenkins, H.; Ford, S.; Green, J. Spreadable Media: Creating Value and Meaning in a Networked Culture, 1st ed.; NYU Press: New York, NY, USA, 2018; pp. 1-352.

60. Rodríguez-López, J.; Aguaded, I. Propuesta metodológica para el análisis del vídeo musical. Quad. CAC 2013, $39,63-70$.

61. Rodríguez-López, J. Audiovisual and semiotics: Music video as text. Signa 2016, 25, 943-958. [CrossRef]

62. Rampazzo-Gambarato, R. How to analyse transmedia narratives? In Baltic Film and Media School Screen Studies; Joesaar, A., Ed.; Tallinn University Press: Tallinn, Estonia, 2012; pp. 1-23.

63. Coombs, T. Transmedia storytelling: A potentially vital resource for CSR communication. Corp. Commun. 2019, 24, 351-367. [CrossRef]

64. Charmaz, K. Constructing Grounded Theory, 2nd ed.; Sage: Thousand Oaks, CA, USA, 2014; pp. 1-746.

65. Abidin, C. Mapping Internet celebrity on TikTok: Exploring attention economies and visibility labours. Cult. Sci. J. 2021, 12, 77-103. [CrossRef] 